\title{
Formação de professores dos Anos Iniciais do Ensino Fundamental: potencialidades e desafios do uso pedagógico das TIC
}

\author{
Karina Oliveira de Freitas - PPGTER/UFSM - karina.freitas@ufsm.br \\ Cláudia Smaniotto Barin - PPGTER/UFSM - claudiabarin@nte.ufsm.br
}

\begin{abstract}
Resumo
Este trabalho objetivou verificar o perfil dos estudantes do quarto semestre do Curso de Licenciatura em Pedagogia (Diurno) da Universidade Federal de Santa Maria (UFSM), matriculados na disciplina de Ciências e Educação I, em relação à maneira como estão sendo formados para a utilização pedagógica das Tecnologias da Informação e da Comunicação (TIC), bem como avaliar a partir do contexto estudado o potencial do gênero História em Quadrinhos (HQ) como recurso de aprendizagem no ensino de ciências. A metodologia foi pautada em uma pesquisa exploratória, de abordagem qualiquantitativa e teve como instrumento de coleta de dados um questionário eletrônico do tipo survey. Os dados demonstraram a predominância de uma abordagem teórica sobre as TIC aplicadas à educação, as quais são tratadas de forma superficial e sem conexão com os demais componentes curriculares. Foi possível traçar um perfil dos estudantes e apontar fragilidades em relação à maneira como estão sendo formados para utilizar as TIC pedagogicamente, além de reconhecer as potencialidades do gênero HQ como recurso de aprendizagem para o ensino de ciências e sugerir aspectos que poderiam ser trabalhados pelo curso de forma mais intensa.
\end{abstract}

Palavras-chave: formação de professores, tecnologias da informação e da comunicação, ensino de ciências, histórias em quadrinhos.

\section{Teacher training in initial grades of elementary education: potentials and challenges of the pedagogical use of ICT}

\section{Abstract}

This study aimed to determine the profile of students in the fourth semester of the Graduation in Pedagogy (Daytime) of the Federal University of Santa Maria (UFSM) enrolled in the discipline of Science and Education I, in relation to how they are being trained for pedagogical use of Information Technology and Communication (ICT), and to evaluate from the context studied the potential of the Comics genre as a learning resource in science teaching. An exploratory research was carried out based on a qualiquantitative approach wherein a survey questionnaire was apllied to the students. Data showed a predominance of a theoretical approach to ICT applied to education, which are treated superficially and without connection with other curriculum components. It was possible to delineate a profile of the students and indicate weaknesses in the way they are being trained to use ICT pedagogically, in addition to recognizing the potential of comics as a learning resource for the teaching of science and suggest ways they could be better worked at course.

Keywords: teacher training, information and communication technology, science teaching, comics.

\section{Introdução}

No atual cenário, cada vez mais nossa atenção cede aos apelos multissensoriais das Tecnologias da Informação e da Comunicação (TIC) presentes em atividades cotidianas. Mudamos nossa forma de pensar e agir, mostramos desinteresse ao estático, a longas e 
lineares leituras sem nenhuma provocação visual, buscamos movimento, sons, cores e interação. Analisando o contexto escolar a situação não é diferente, tornando-se fundamental que os sujeitos envolvidos apropriem-se criticamente dessas tecnologias como mediadoras no processo de ensino e aprendizagem, principalmente pelas suas possibilidades de flexibilizar e potencializar a comunicação e a interação entre estudantes e professores.

Pesquisas realizadas por Tapscott (1999) identificaram oito mudanças na maneira como os jovens pensam e trabalham provocadas pela interatividade na aprendizagem, são elas: (i) a passagem do modelo linear para o hipermídia; (ii) de instrução para construção e descoberta; (iii) de centrada no professor para centrada no aluno; (iv) de absorção de material para aprendizagem de como navegar e de como aprender; (v) de 'aprendizagem escolar' para aprendizagem por toda a vida; (vi) de modelo único para respeito à diversidade; (vii) de aprendizagem como tortura para aprendizagem como prazer e (viii) de professor como transmissor para professor como facilitador.

Nesse contexto, Takahashi (2000) alerta para a necessidade de um dinâmico processo de revisão curricular incluindo-se as licenciaturas, nas quais, a inserção das TIC deve ser enérgica, porém ponderada, para familiarizar os futuros professores com o uso dessas tecnologias. As principais políticas públicas que regulamentam a educação no Brasil, em todos os níveis e modalidades, preveem a incorporação das TIC no processo de ensino e aprendizagem. Como exemplo, destacam-se as Diretrizes Curriculares Nacionais (DCN) para a Formação de Professores da Educação Básica, em nível superior, curso de licenciatura, de graduação plena, as quais estabelecem que a organização curricular de cada instituição deve observar o preparo para "o uso de tecnologias da informação e da comunicação e de metodologias, estratégias e materiais de apoio inovadores.” (Brasil, 2002, p. 4).

As DCN para os Cursos de Licenciatura em Pedagogia, os quais formam profissionais para atuar na Educação Infantil e nos Anos Iniciais do Ensino Fundamental, também reconhecem a importância da inserção das tecnologias na prática docente ao estabelecerem que os egressos do curso deverão demonstrar domínio das TIC sendo capazes de relacionar pedagogicamente as linguagens dos meios de comunicação com a educação (Brasil, 2006).

Nesse sentido, os conteúdos abordados em ciências nos Anos Iniciais do Ensino Fundamental são importantes, pois servem de base para a compreensão da sociedade e das relações entre ciência e tecnologia. Porém, de acordo com Bizzo (2009), as aulas estão limitadas a reprodução e memorização de conceitos distanciando-se da ideia de ensinar ciências para que a criança aprenda de forma significativa e ativa.

Os professores são, portanto, desafiados a incorporar à sua prática conhecimentos de ciência e tecnologia significativos para a formação dos estudantes (Delizoicov et al., 2002). Nesse sentido, Santos (2007) destaca os principais benefícios do uso das TIC no ensino de ciências: (i) os conteúdos tornam-se mais interessantes, autênticos e relevantes; (ii) há mais tempo dedicado à observação, discussão e análise; e (iii) existem mais oportunidades para implementar situações de comunicação e colaboração.

De acordo com as DCN para o Ensino Fundamental de 09 anos fica em evidência que "a recuperação do caráter lúdico do ensino contribuirá para melhor qualificar a ação pedagógica junto às crianças, sobretudo nos anos iniciais dessa etapa da escolarização" (Brasil, 2010, p. 8). Estudos sobre o ensino de ciências têm reconhecido o gênero História em Quadrinhos (HQ) como recurso didático relevante a esta área de ensino e aplicável a todos os níveis. Pizzarro e Lopes (2010) situam os 
quadrinhos como meio de divulgação e alfabetização científica que proporcionam aos estudantes a experiência com diferentes fontes de informação e estruturas de argumentação que vão além do livro didático ampliando seu repertório sociocientífico. Nesse sentido, "a mistura de ciência e quadrinhos pode contribuir para a construção da cidadania dos jovens” (Caruso e Silveira, 2009, p. 218).

Considerando que a cidadania também se relaciona com o acesso às tecnologias produzidas pela sociedade, Rota e Izquierdo (2003), argumentam que os benefícios do uso dos quadrinhos no processo de ensino e aprendizagem são potencializados com a utilização do computador nesse contexto. Para além do computador, a Internet consegue agrupar vários recursos multimidiáticos em um mesmo ambiente, associando som, imagem e animação, abrangendo, assim, diferentes funções e estilos de aprendizagem.

Com base nos pressupostos apresentados, esta pesquisa objetivou verificar o perfil dos estudantes do quarto semestre do Curso de Licenciatura em Pedagogia (Diurno) da Universidade Federal de Santa Maria (UFSM), matriculados na disciplina de Ciências e Educação I, em relação à maneira como estão sendo formados para a utilização pedagógica das TIC, bem como avaliar a partir do contexto estudado o potencial do gênero HQ como recurso de aprendizagem no ensino de ciências.

\section{Metodologia}

Este trabalho caracteriza-se como uma pesquisa exploratória, na qual foi utilizado como instrumento de coleta de dados um questionário do tipo survey com questões abertas e fechadas, de natureza quali-quantitativa. Segundo Gil (2010), a pesquisa exploratória é realizada sobre um problema ou questão de pesquisa para melhor compreendê-lo ou construir hipóteses. O questionário foi elaborado a partir da ferramenta Formulário do Google Drive e aplicado, entre os meses de setembro e outubro de 2014, aos estudantes do quarto semestre do Curso de Licenciatura em Pedagogia (Diurno) da UFSM matriculados na disciplina de Ciências e Educação I. Os formulários foram enviados por e-mail aos estudantes, cujos endereços foram obtidos a partir do banco de dados da Universidade. A seguir serão apresentados e discutidos os resultados obtidos.

\section{Resultados e discussões}

Foram enviados 54 formulários, obtendo uma taxa de resposta de 29,63\%. Entre os respondentes $93,75 \%$ é do sexo feminino e a idade média é de 22 anos. Com a finalidade de introduzir a temática do estudo, os estudantes foram questionados se, acreditam que a utilização da tecnologia disponível para trabalhar conteúdos em sala de aula possa contribuir para o processo de ensino e aprendizagem. Todos foram unânimes, respondendo de forma afirmativa à questão.

Ao serem questionados se o Curso de Licenciatura em Pedagogia (Diurno) oferece disciplinas que preparem para o uso pedagógico das TIC no contexto escolar, $75 \%$ responderam positivamente, enquanto $25 \%$ afirmam não reconhecer disciplinas com esta natureza no curso (Gráfico 1). Todos que responderam "sim" à questão anterior indicaram a disciplina de TIC Aplicadas à Educação para justificar sua resposta. 


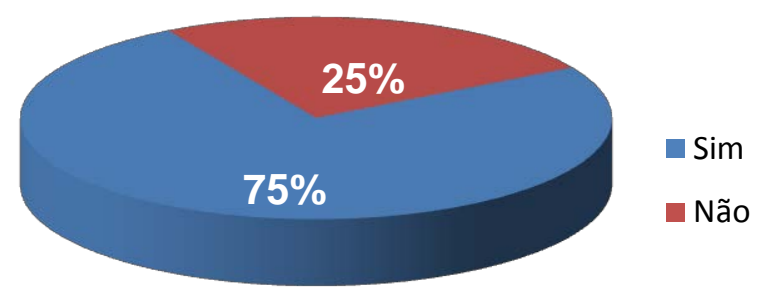

Gráfico 1- Percepção dos estudantes sobre a formação para utilização pedagógicas das TIC no Curso de Licenciatura em Pedagogia (Diurno) - UFSM

Embora reconhecida a importância de componentes curriculares com esta natureza nos cursos de formação de professores, acredita-se que o compromisso em capacitar os estudantes para o uso pedagógico das TIC deva perpassar o currículo de modo geral e não apenas ser atribuído a uma disciplina específica e isolada das demais. Os cursos de licenciatura devem estar atentos a essa questão, pois conforme Barin et al. (2012) nestes cursos a utilização das TIC não se dá numa perspectiva transformadora, havendo carência de comunicação entre as disciplinas formativas e pedagógicas.

Essa preocupação com a capacitação para uso das tecnologias faz parte do perfil dos estudantes que responderam o questionário, pois $93,75 \%$ deles consideram importante que os cursos de formação de professores preparem para utilizar as TIC pedagogicamente em sala de aula (Gráfico 2). Em contrapartida, para alguns autores (Lopes; Feitosa, 2011; Karsenti et al., 2008; Belintane, 2002) muitos alunos de cursos de licenciaturas não estão sendo formados para utilizar essas tecnologias para fins pedagógicos, diminuindo assim, as chances de integrá-las às suas práticas posteriormente.

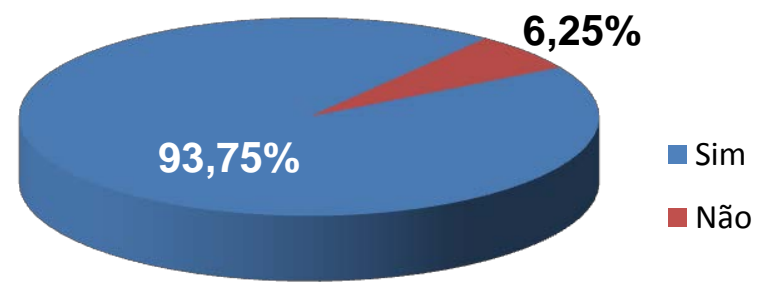

Gráfico 2- Opinião dos estudantes sobre a importância da formação para utilização pedagógica das TIC em cursos de licenciatura

O Quadro 1 sintetiza as afirmativas e os respectivas números e porcentagens de respostas dos estudantes para a questão que procurou identificar quais atividades proporcionaram contato com as TIC aplicadas à educação durante sua formação. A soma das respostas é maior do que $100 \%$ pois nesta questão era possível selecionar mais de uma alternativa. 


\begin{tabular}{|l|c|c|}
\hline \multicolumn{1}{|c|}{$\begin{array}{c}\text { Dentre as atividades listadas abaixo, de quais delas você teve oportunidade de } \\
\text { participar durante sua formação? }\end{array}$} & $\begin{array}{c}\text { Porcentagem } \\
\text { Alternativas }\end{array}$ & $\begin{array}{c}\text { Número } \\
\text { respostas }\end{array}$ \\
\hline \multicolumn{1}{|c|}{\begin{tabular}{c}
\multicolumn{1}{|c|}{} \\
As disciplinas do curso abordam teorias sobre TIC aplicadas à educação.
\end{tabular}} & $87,50 \%$ & 14 \\
\hline $\begin{array}{l}\text { As disciplinas do curso proporcionam atividades práticas utilizando TIC } \\
\text { aplicadas à educação. }\end{array}$ & $43,75 \%$ & 7 \\
\hline Participo/participei de projetos de pesquisa sobre o tema. & $0,00 \%$ & 0 \\
\hline Participo/participei de projetos de extensão sobre o tema. & $0,00 \%$ & 0 \\
\hline Participo/participei de monitorias que exigem conhecimento sobre o tema. & $0,00 \%$ & 0 \\
\hline Participei de oficinas, congressos, encontros que abordaram o tema. & $6,25 \%$ & 1 \\
\hline Nenhuma. & $0,00 \%$ & 0 \\
\hline Outros. & $0,00 \%$ & 0 \\
\hline
\end{tabular}

Quadro 1 - Oportunidades de capacitação para uso das TIC aplicadas à educação oferecidas durante o Curso de Licenciatura em Pedagogia (Diurno) - UFSM.

Nessa questão a alternativa mais assinalada indica que as disciplinas do curso abordam teorias sobre TIC aplicadas à educação (87,50\%), enquanto apenas 43,75\% relatam que as disciplinas do curso proporcionam atividades práticas utilizando as TIC pedagogicamente. Dessa forma, os dados sugerem que no curso há predominância de uma abordagem teórica sobre o tema e alertam para o fato de que uma formação completa também deve ser pautada em conhecimentos práticos, uma vez que o próprio Projeto Pedagógico de Curso (PPC) destaca que os conhecimentos construídos pelo estudante nessas disciplinas permitirão a visualização dos princípios teóricos, suas aplicabilidades e implicações ao inserirem-se em sala de aula (UFSM, 2007).

$\mathrm{Na}$ questão seguinte, os estudantes também poderiam assinalar mais de uma opção para relatar quais tecnologias seus professores costumam utilizar durante as aulas. Os dados estão sintetizados no Quadro 2.

\begin{tabular}{|l|c|c|}
\hline \multicolumn{1}{|c|}{$\begin{array}{c}\text { Quais dessas tecnologias seus professores costumam utilizar durante as } \\
\text { aulas? }\end{array}$} & $\begin{array}{c}\text { Porcentagem } \\
\text { respostas }\end{array}$ & $\begin{array}{c}\text { Número } \\
\text { respostas }\end{array}$ \\
\hline \multicolumn{1}{|c|}{$\begin{array}{c}\text { Alternativas } \\
\text { Projetor multimídia. }\end{array}$} & $87,50 \%$ & 14 \\
\hline Ferramentas para apresentação de slides (ex: PowerPoint, Prezi, Slideshow). & $93,75 \%$ & 15 \\
\hline Ferramentas de busca (ex: Google). & $81,25 \%$ & 13 \\
\hline Ferramentas para escrita colaborativa (ex: Wiki, Google Drive). & $56,25 \%$ & 9 \\
\hline Ferramentas para bate-papo (ex: WhatsApp, Messenger, Skype). & $0,00 \%$ & 0 \\
\hline Ferramentas para elaboração de mapas conceituais (ex: CmapTools). & $12,50 \%$ & 2 \\
\hline Vídeos, filmes e outros recursos audiovisuais. & $75,00 \%$ & 12 \\
\hline Ambientes Virtuais de Ensino-Aprendizagem (ex: Moodle). & $81,25 \%$ & 13 \\
\hline Redes sociais (ex: Facebook, Instagram, Twitter). & $18,75 \%$ & 3 \\
\hline Mundos virtuais (ex: SecondLife). & $12,50 \%$ & 2 \\
\hline Lousa digital. & $0,00 \%$ & 0 \\
\hline E-mail. & $81,25 \%$ & 13 \\
\hline Blog. & $0,00 \%$ & 0 \\
\hline Nenhuma. & $0,00 \%$ & 0 \\
\hline Outro. & $0,00 \%$ & 0 \\
\hline
\end{tabular}

Quadro 2 - Utilização de tecnologias pelos professores do Curso de Licenciatura em Pedagogia (Diurno) - UFSM 
De acordo com as respostas obtidas os recursos mais utilizados pelos professores são: Ferramentas para apresentação de slides, como Power Point, Prezi, Slide Show (93,75\%) seguidas do Projetor Multimídia (87,50\%). É comum que exista uma estreita relação entre esses dois recursos, pois atualmente, a metodologia baseada na técnica de apresentação de slides associada a um projetor multimídia como recurso tecnológico predomina entre os professores universitários. O desafio está em fugir das aulas expositivas e tradicionais ao optar por essas duas ferramentas, pois "projeções de slides, se não forem bem planejadas, podem apenas reproduzir o quadro negro e o giz sem apresentarem inovação alguma” (Bastos et al., 2013, p. 6).

Em seguida, são citadas Ferramentas de busca, Ambientes Virtuais de EnsinoAprendizagem (AVEA) e E-mail em 81,25\% das respostas. As ferramentas de busca podem ser ótimas fontes de pesquisa, mas o professor deve ser cauteloso ao propor atividades deste tipo, pois com a hipertextualidade dos conteúdos disponíveis na rede, o estudante pode ser atraído a percorrer outros caminhos e acabar por dispersar-se, fugindo do foco da pesquisa. Dessa forma, atividades que envolvam ferramentas de busca, como o Google, por exemplo, devem ter objetivos bem estabelecidos e uma constante orientação do professor.

Com a convergência entre as modalidades de ensino tem se tornado cada vez mais comum a utilização dos AVEA como apoio as disciplinas dos cursos presenciais, porém, muitas vezes em função da falta de capacitação dos professores para utilizar esses ambientes, as suas potencialidades deixam de ser exploradas limitando-os a função de repositório de conteúdos pelos professores e/ou um meio para a entrega online de atividades e trabalhos pelos estudantes.

Na sequência das respostas mais assinaladas aparecem os Vídeos, filmes e outros recursos audiovisuais (75,00\%). A utilização desses recursos pode ser uma boa estratégia, desde que tenham um propósito bem definido e uma intencionalidade educacional dentro do planejamento do professor e permitam que os estudantes analisem e discutam sobre o conteúdo apresentado. Caso contrário, acabam sendo pouco significativos para os estudantes se o professor os utiliza apenas como uma saída para uma aula mal planejada ou sem planejamento algum.

Em contraste, houve poucos indícios do uso de Redes sociais (18,75\%), Ferramentas para elaboração de mapas conceituais (12,50\%), Mundos virtuais (12,50\%), Lousa digital e Blog (0,00\%). A baixa ou inexistente representatividade dessas ferramentas na metodologia dos professores do curso pode sugerir a falta de conhecimento quanto à sua existência e, até mesmo, a falta de capacitação quanto às formas de utilização. Na questão subsequente, 68,75\% dos estudantes afirmaram ter tido a experiência de produzir material didático durante as disciplinas do curso (Gráfico 3). Entre as disciplina mais citadas estão a de TIC Aplicadas à Educação, seguida de Gestão da Educação Básica, Didática e Oralidade, Leitura e Escrita e, ainda, da Disciplina Complementar de Graduação (DCG) AVEA. 


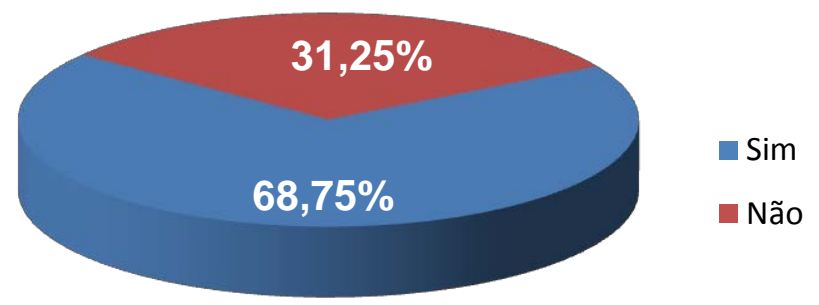

Gráfico 3- Experiência de produção de material didático durante o curso

Observamos falta de clareza do grupo em relação ao conceito de material didático, uma vez que, ao responder o questionário alguns estudantes consideraram a elaboração de planos de aula a partir de editores online/off-line e a apresentação de trabalhos utilizando Google Drive e Prezi como produção de material didático, o que pode ser demonstrado no comentário abaixo:

\begin{abstract}
“A disciplina de TIC's, porém não foi o suficiente, se tratou de algo muito superficial uma vez que tivemos que montar um plano de aula usando algumas das tecnologias. E não foi algo nem aplicado ou ao menos revisado." (Estudante A).
\end{abstract}

Na sequência, ao serem questionados se o gênero literário história em quadrinhos tem potencial para ser utilizado em sala de aula, todos foram unânimes em reconhecer as potencialidades desse recurso. No entanto, ao investigar se em alguma disciplina, o professor utilizou história em quadrinhos como recurso de aprendizagem apenas 18,75\% responderam que "sim” (Gráfico 4).

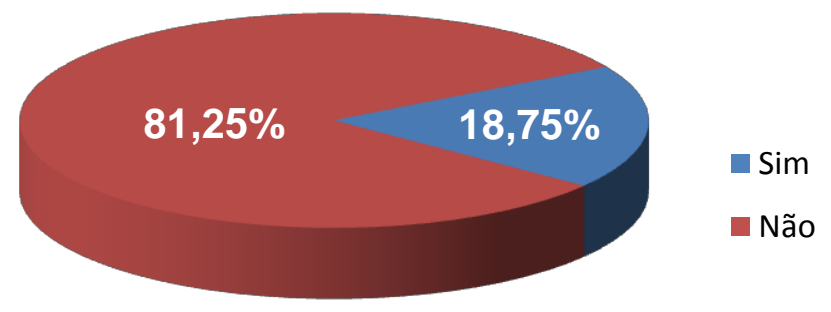

Gráfico 4- Representatividade de utilização das HQ pelos professores do curso como recurso de aprendizagem

Com base nestes dados, percebeu-se que ainda existem muitas potencialidades das HQ a serem exploradas, pois, dentre as disciplinas destacadas por indicar o uso deste recurso na metodologia dos professores, os relatos revelam que foram utilizadas de forma superficial e com caráter explicativo apenas para elucidar conceitos, como pode ser observado nas falas abaixo:

\footnotetext{
“Na de Comunicação em Língua Portuguesa, mas só foi para explicar um dos gêneros textuais. Algo bem superficial também.” (Estudante B).

"Na disciplina de ciência e educação onde utilizou da historia como comparação de uma teoria.” (Estudante C).
} 
Embora, até o momento, o gênero HQ tenha sido pouco explorado como recurso de aprendizagem pelos professores do curso, avaliou-se como positivo o dado de que na opinião de $87,50 \%$ dos respondentes este gênero pode facilitar a aprendizagem de conteúdos de ciências (Gráfico 5).

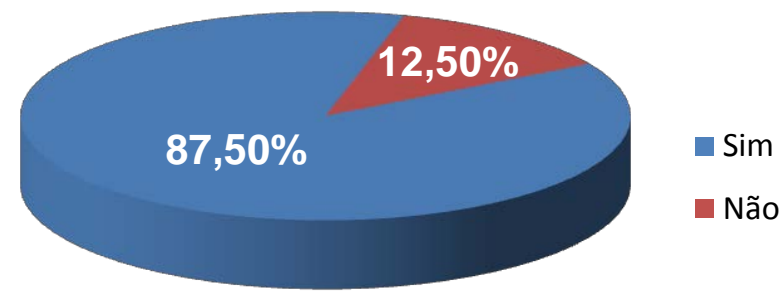

Gráfico 5- Opinião dos estudantes sobre a utilização das HQ como facilitadoras da aprendizagem no ensino de ciências

Quando questionados sobre quais conteúdos das ciências poderiam ser trabalhados utilizando histórias em quadrinhos surgiram as seguintes temáticas: água, fotossíntese, meio ambiente, reciclagem, sustentabilidade, animais e higiene. Para elucidar a questão destaca-se, abaixo, a opinião de um dos estudantes:

\footnotetext{
"Acredito que todos, é possível adaptar o conteúdo em histórias em quadrinhos de uma forma que se torne divertido e mais eficaz o aprendizado de determinado conteúdo." (Estudante $D$ ).
}

Ao serem questionados se já haviam lido alguma história em quadrinhos no formato digital, 56,25\% afirma não ter tido contato com este tipo de leitura (Gráfico 6).

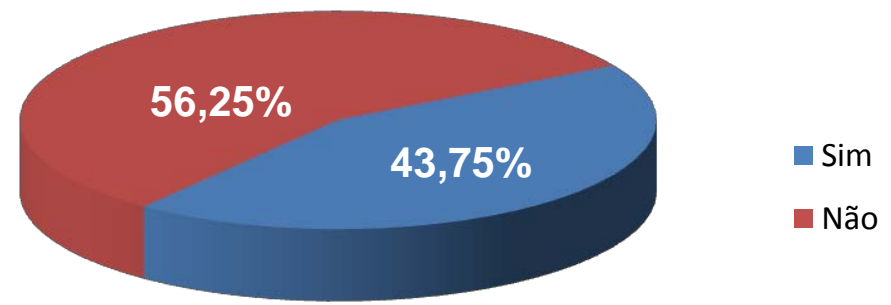

Gráfico 6- Vivência dos estudantes com a leitura de HQ digitais

O Quadro 3 demonstra pouco conhecimento sobre softwares e editores online para produção de HQ considerando que $81,25 \%$ dos estudantes não conhece nenhuma das ferramentas citadas nas alternativas. Apenas 6,25\% conhece o Toondoo e 12,50\%, o HagáQuê. O questionário finalizou-se com a seguinte questão: Se durante o curso fossem ofertadas oficinas gratuitas sobre produção de histórias em quadrinhos digitais você participaria? Procurou-se com isso, fazer um levantamento do interesse do grupo nesta temática, no qual o retorno recebido foi avaliado como positivo, pois todos os estudantes mostraram-se interessados em participar, o que aumenta a motivação e a responsabilidade em relação a trabalhos futuros. 


\begin{tabular}{|l|c|c|}
\hline \multicolumn{1}{|c|}{$\begin{array}{c}\text { Abaixo estão listados alguns softwares e editores online para a } \\
\text { produção de histórias em quadrinhos. Você conhece algum deles? }\end{array}$} & $\begin{array}{c}\text { Porcentage } \\
\text { m respostas }\end{array}$ & $\begin{array}{c}\text { Número } \\
\text { respostas }\end{array}$ \\
\cline { 1 - 2 } \multicolumn{1}{|c|}{ Alternativas } & $6,25 \%$ & 1 \\
\hline Toondoo & $12,50 \%$ & 2 \\
\hline HagáQuê & $0,00 \%$ & 0 \\
\hline Pixton & $0,00 \%$ & 0 \\
\hline Scratch. & $0,00 \%$ & 0 \\
\hline WittyComics & $0,00 \%$ & 0 \\
\hline MakeBeliefsComix.com & $0,00 \%$ & 0 \\
\hline MarvelKids.com & $0,00 \%$ & 0 \\
\hline Strip Generator & $0,00 \%$ & 0 \\
\hline Pikistrips & $81,25 \%$ & 13 \\
\hline Nenhum & $0,00 \%$ & 0 \\
\hline Outros. Qual? &
\end{tabular}

Quadro 3 - Conhecimentos dos estudantes do Curso de Licenciatura em Pedagogia (Diurno) UFSM sobre softwares e editores online para produção de histórias em quadrinhos

\section{Considerações finais}

Os dados sugerem que os objetivos da pesquisa são pertinentes, pois os estudantes relatam que nas disciplinas do curso há predomínio de conhecimentos teóricos sobre as TIC aplicadas à educação, além de serem abordados de forma superficial e sem conexão com os demais componentes curriculares.

Dessa forma, apesar deste estudo caracterizar-se como exploratório e apresentar limitações inerentes a este tipo de pesquisa, a partir dos dados obtidos com o questionário foi possível traçar um perfil inicial dos estudantes do Curso de Licenciatura em Pedagogia (Diurno) da UFSM em relação à maneira como estão sendo formados para utilizar as TIC pedagogicamente, além de reconhecer as potencialidades do gênero HQ como recurso de aprendizagem para o ensino de ciências.

Foi possível, ainda, identificar fragilidades na formação destes estudantes em relação ao uso pedagógico dessas tecnologias e sugerir aspectos que poderiam ser abordados de forma mais minuciosa durante o curso, como por exemplo, tornar mais claro o conceito de material didático, estimular sua produção e explorar as potencialidades do gênero HQ apoiado por tecnologias para trabalhar conteúdos de ciências, incluindo os apontados neste estudo exploratório.

\section{Referências bibliográficas}

BARIN, C. S.; ELLENSOHN, R. M.; MULLER, L. Construção de significados e interação com, no e pelo computador: estudos problematizados no AVEA Moodle sobre uso das tecnologias da informação e comunicação. Revista Novas Tecnologias na Educação, v. 10, p. 1-11, 2012. 
BASTOS, G. D.; FREITAS, K. O.; MARSHALL, D. BARIN, C. S. Os egressos do Curso de Licenciatura em Ciências Biológicas da Universidade Federal de Santa Maria e as TIC: um estudo exploratório. Revista Novas Tecnologias na Educação, v. 11, N. 3, 2013.

BELINTANE, C. Por uma ambiência de formação contínua de professores. Cadernos de Pesquisa. n. 117, p. 177-193, 2002.

BIZZO, N. M. V. Ciências: Fácil ou difícil? 1 ed. São Paulo: Biruta, 2009.

BRASIL. Ministério da Educação, Conselho Nacional de Educação. Resolução CNE/CEB, de 14 de dezembro de 2010. Fixa Diretrizes Curriculares Nacionais para o Ensino Fundamental de 9 (nove) anos. Brasília, 2010.

Ministério da Educação, Conselho Nacional de Educação. Resolução

$\overline{\mathbf{C N E} / \mathbf{C P}}$ 1, de 15 de maio de 2006. Institui Diretrizes Curriculares Nacionais para o Curso de Graduação em Pedagogia, licenciatura. Brasília, 2006.

Ministério da Educação, Conselho Nacional de Educação. Resolução

$\overline{\mathbf{C N E} / \mathbf{C P}}$ 1, de 18 de fevereiro de 2002. Institui Diretrizes Curriculares Nacionais para a Formação de Professores da Educação Básica, em nível superior, Curso de Licenciatura, de graduação plena. Brasília, 2002.

CARUSO, F.; SILVEIRA, C. Quadrinhos para a cidadania. História, Ciências, Saúde. Manguinhos, Rio de Janeiro, v.16, n.1, jan.-mar, p. 217-236, 2009.

DELIZOICOV, D.; ANGOTTI, J. A. P.; PERNAMBUCO, M. M. Ensino de Ciências: fundamentos e métodos. São Paulo: Cortez, 2002.

GIL, A. C. Como elaborar projetos de pesquisa. 5 ed. São Paulo, SP: Atlas, 2010.

KARSENTI, T.; VILLENEUVE, S.; RABY C. O uso pedagógico das Tecnologias da Informação e da Comunicação na formação dos futuros docentes no Quebec. Educação e Sociedade, Campinas, v. 29, n. 104, p. 865-889, out. 2008.

LOPES, R.; FEITOSA, E. Estágio extracurricular como um possível espaço de formação do professor para uso de tecnologias. Revista Ciência em Extensão. v.7, n.2, 2011.

PIZZARRO, M. V., LOPES, J, J. Os indicadores de alfabetização científica nos anos iniciais do ensino fundamental e o uso da história em quadrinhos como recurso didático em ciências. In: BASTOS, F. (Org.) Ensino de ciências e matemática III: contribuições da pesquisa acadêmica a partir de múltiplas perspectivas [online]. São Paulo: Editora UNESP; São Paulo: Cultura Acadêmica, 2010. 214 p.

ROTA, G; IZQUIERDO, J. Comics as tool for teaching biotechnology in primaryschool. Eletronic Journal of Biotechonology, v. 6, n. 2, p. 86-89, 2003.

SANTOS, A. As TIC e o desenvolvimento de competências para aprender a aprender : um estudo de caso de avaliação do impacte das TIC na adopção de métodos de trabalho efectivos no $1^{\circ}$ ciclo do ensino básico. Dissertação de Mestrado. Aveiro: Universidade de Aveiro, Portugal, 2007.

TAKAHASHI, T. (org). Sociedade da informação no Brasil: livro verde. Brasilia: Ministerio da Ciencia e Tecnologia, 2000.

TAPSCOTT, Don. Geração Digital: A crescente e irreversível ascensão da Geração Net. São Paulo: Makron Books, 1999.

UNIVERSIDADE FEDERAL DE SANTA MARIA. Projeto Pedagógico do Curso de Licenciatura em Pedagogia (Diurno). 2007. 